\title{
VARIAÇÕES DA TEMPERATURA DA ÁGUA DE UM PEQUENO LAGO ARTIFICIAL AO LONGO DE UM ANO EM PIRACICABA - SP
}

\author{
L. R. ANGELOCCI, ${ }^{1,2}$ N. A. VILLA NOVA \\ 'Depto. de Fisica e Meteorologia - ESALQ/USP - C.P. 9, CEP 13.418-900 - Piractcaba, SP \\ 'Bolsisla do CNPq
}

\begin{abstract}
RESUMO: Foram estudadas as variaçzes térmicas da agua em quatro profundidades $(0,10 ; 0,30 ; 0,60$ e 1,20 m) em um pequeno lago artificial situado no municipio de Piracicaba-SP, entre agosto de 1987 e agosto de 1988, como subsidio a aquacultura e manejo de anfíbios em cativeiro. Independente das amplitudes térmicas do ar serem ou måo elevadas, ao longo de um dia as flutuaçoes termicas na água foram pequenas, sendo que no perfodo diurno foram maiores nas duas menores profundidades, principalmente entre agosto ejaneiro. Em dias de alta irradiancia solar a temperatura da água mostrou-se superior a do ar na maior parte do dia e em dias churosos ou muito nublados isso ocorreu no dia inteiro. Em consequencia, as temperaturas medias diarias da água em todas as profundidades mostraram-se sistematicamente, com poncas exceçoes, superiores i do ar em todos os meses. Houve maior estratificaģăo térmica do lago no perfodo entre agosto e janeiro. Sâo discutidas as relaçóes do regime térmico do lago com elementos meteorológicos e apresentados valores extremos diśrios e anuais de temperatura da agua.

Descritores: temperatura da agua, Lago
\end{abstract}

\section{WATER TEMPERATURE VARIATIONS DURING ONE YEAR IN A SMALL LAKE AT PIRACICABA - SP, BRAZIL}

\begin{abstract}
Thermal variations of water at four depths $(0.10 ; 0.30 ; 0.60$ and $1.20 \mathrm{~m})$ in a small lake of the Piracicaba county, São Paulo State, Brazil, were measured during the period of August 1978 to August 1988, as a subsidy to the aquaculture and the husbandry of amphibla in captivity. During a day, the thermal fluctuations of water were small, independently of the air temperature amplitude; in the daytime fluctuations were greater at the depths of 0.10 and $0.30 \mathrm{~m}$, mainly in the period August-January. In clear days the temperature of water was greater than that of the air in most of the day, while in cast or rainny days this fact occurred all day. Consequently, daily mean temperatures of water at the four depths of measurement were greater than the daily mean air temperatures, except for a few days. Thermal stratification was more pronounced in the period August-January. The relationships between thermal nuctuations of water and meteorological elements are discussed, and the daily and annual absolute minimum and maximum temperatures of water are presented.
\end{abstract}

Key Words: temperature of water, Lake

\section{INTRODUÇĀO}

O regime térmico dos corpos d'água na natureza tem grande importância ecológica devido às interações entre a temperatura $e$ a vida aquática. Segundo WHEATON (1987), a temperatura da água provavelmente tem maior influência sobre a vida $e$ os sistemas aquáticos do que qualquer outra variável tomada isoladamente. Pelo fato da temperatura afetar a solubilidade dos gases na água, o aquecimento desta a empobrece em oxigênio, influenciando assim a decomposição de matéria orgânica, com consequente efeito sobre a qualidade do líquido $e$ sobre a vida de organismos aeróbios aquáticos
(BRANCO, 1986). A temperatura a feta, também, o crescimento e o desenvolvimento dos seres vivos, devido a sua influência sobre as reações químicas, em graus e formas dependentes da especie. No reino animal, por exemplo, há formas diferentes de termorregulação entre as espécies, que permitem classificá-las de modo genérico em dois grandes grupos: os homeotérmicos, cuja temperatura corporal depende de sua propria atividade metabólica e os poiquilotérmicos, cuja temperatura corporal aproxima-se a do ambiente em que vivem, sendo o calor metabólico de menor importância do que o calor do ambiente em determinar sua temperatura corporal (HARDY, 1979). Os vegetais 
tendem, tambem, a ter sua temperatura próxima do ambiente em que vivem.

Para os seres de ambos os grupos acima, a temperatura $e$ fator determinante do seu crescimento e desenvolvimento. Nos poiquilotérmicos, como resultado da inexistência de mecanismo proprio de manutenção de sua temperatura corporal, o efeito da temperatura ambiente sobre o crescimento, desenvolvimento e sobrevivencia 6 marcante. No caso de poiquilotérmicos aquáticos, sejam invertebrados, como por exemplo insetos cuja fase larval ocorre na agua, sejam vertebrados como os peixes, a velocidade das reaçòes orgãnicas é determinada pela temperatura da água, existindo exigências térmicas delimitadas por temperaturas basais em que ocorre desenvolvimento, faixas de tolerância, zonas de resistência (tolerância a regimes térmicos desfavoráveis por um tempo definido) e temperaturas letais. Até certo ponto, essas exigências podem ser variáveis dentro de uma espécie em função de sua aclimatação ou pela adaptaçào à diferentes habitats (HARDY, 1979; WHEATON, 1987).

Nos crocodilianos, como outro exemplo de animais exotérmicos, o estilo de vida anfíbio, com procura frequente da água, tem funçào termorreguladora (LANG, 1987). Neles, características como o processo de alimentaçào e a taxa de crescimento, são determinadas pela temperatura corporal (VERDADE et al., 1992) e o regime térmico de corpos d'água que fazem parte do seu habitat acaba sendo um fator fundamental na vida desses animais.

O conhecimento do regime térmico de pequenos corpos d'água e dos fatores que o a fetam é de grande interesse aquacultural e no manejo de anfibios em cativeiro.

O regime térmico de corpos d'água situados no continente depende fundamentalmente do regime de energia radiante disponivel e da propagaçào de calor na água, sendo o transporte de massa do proprio líquido a forma mais eficiente de propagação calorífica. A coluna de água pode ficar estratificada térmicamente de diferentes formas, com padrōes variáveis mesmo dentro de uma regiāo, em funçãode elementos climáticos, como radiação solar e ventos, e de fatores específicos do ecosssistema, como sua morfometria (ESTEVES, 1988).

Tendo em vista o interêsse que o regime térmico natural de um pequeno corpo d'água pode apresentar para a aquacultura, para o manejo de crocodilianos em condiçōes de cativeiro e para outros tipos de aplicações, são mostrados neste trabalho resultados da variação temporal e espacial (em profundidade) da temperatura da água de um pequeno lago artificial na região de Piracicaba-SP, ao longo de um ano.

\section{MATERIAL E MÉTODOS}

O estudo foi realizado em um lago artificial de forma irregular, com superfície de $7802 \mathrm{~m}^{2}$, com a maior dimensão no sentido N-S de $110 \mathrm{~m}$, situado no campus Luiz de Queiroz da USP, em Piracicaba-

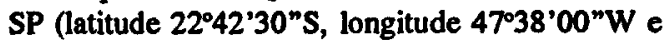
altitude $546 \mathrm{~m}$ ). A profundidade do corpo d'água era de $0,305 \mathrm{~m}$ nas suas bordas e de 1,285 $\mathrm{m}$ na sua regiāo central na época do início das medidas, em agosto de 1987. Essa profundidade variou ao longo do período de medida, entre agosto de 1987 e agosto de 1988, em função das chuvas e da evapotranspiração, em cerca de $0,03 \mathrm{~mm}$ para menos até $0,10 \mathrm{~m}$ para mais em relação ao início das medidas.

A temperatura da água foi medida em 141 dias no período, a intervalos médios de 1 hora, dos quais 108 dias com medidas nas 24 horas. Foram usados termopares de cobre-constantan (diâmetro de $0,51 \mathrm{~mm}$ ) com isolamento térmico, sendo as junções instaladas dentro de um tubo de alumínio de diâmetro interno de $63,5 \mathrm{~mm}$, com aquisição do sinal em registrador potenciométrico marca Honeywell, o qual era acionado nos horários determinados para medida através de um temporizador. As junções dos termopares foram fixadas nas profundidades 0,$10 ; 0,30 ; 0,60$ e 1,20 $\mathrm{m}$, instalando-se 2 termopares por profundidade e tirando-se a média das duas medidas para cada profundidade. Tendo-se o nível do espelho d'água variado com o tempo, as profundidades efetivas de medida variaram de $-0,03 \mathrm{~m} \mathrm{a}+0,10 \mathrm{~m} \mathrm{em}$ torno das profundidades acima. Para facilidade de apresentação dos resultados, as profundidades serão a partir daqui designadas como 10, 30,60 e 120 $\mathrm{cm}$. Os gráficos obtidos no registro tinham escala graduada de $0,5^{\circ} \mathrm{C}$, sendo as graduações inferiores a essas obtidas por interpolação no gráfico.

Os dados meteorológicos foram coletados na estação climatológica do campus, sendo a temperatura e a umidade relativa do ar medidas através de um termohigrbgrafo em abrigo-padrão, a velocidade do vento atraves de um anembgrafo 
universal, a radiação solar atravts de um actinógrafo bimetálico tipo Robitsch e o número de horas de brilho solar através de um heliografo tipo CampbellStokes.

\section{RESULTADOS E DISCUSSÃo}

Variaçōes ao longo de um dia: As variações temporais da tenperatura do ar e da água nas diferentes profundidades, obtidas a partir das leituras efetuadas a cada hora, para uma sequência de dias com condições meteorológicas variáveis nos meses de outubro e novembro de 1987 e de abril e julho de 1988, são mostradas nas figuras 1 e 2 , a título de exemplos.
Os dados mostram a já conhecida capacidade da água de reter calor, devido a sua alta capacidade calorífica, o que contribue para que as flutuações térmicas da massa líquida sejam bem mais atenuadas que a do ar, nas escalas diária e sazonal. Indicam, tambem, que a variação da temperatura da água nas várias profundidades dependeu das variações sequenciais das condiçòes meteorológicas do dia em questão e dos dias anteriores, principalmente quanto à irradiância solar.

A sequência mostrada para o mês de outubro, indica que no dia 02 , a flutuação térmica na água foi muito pequena em consequência da baixa irradiância solar, com pequena variação entre
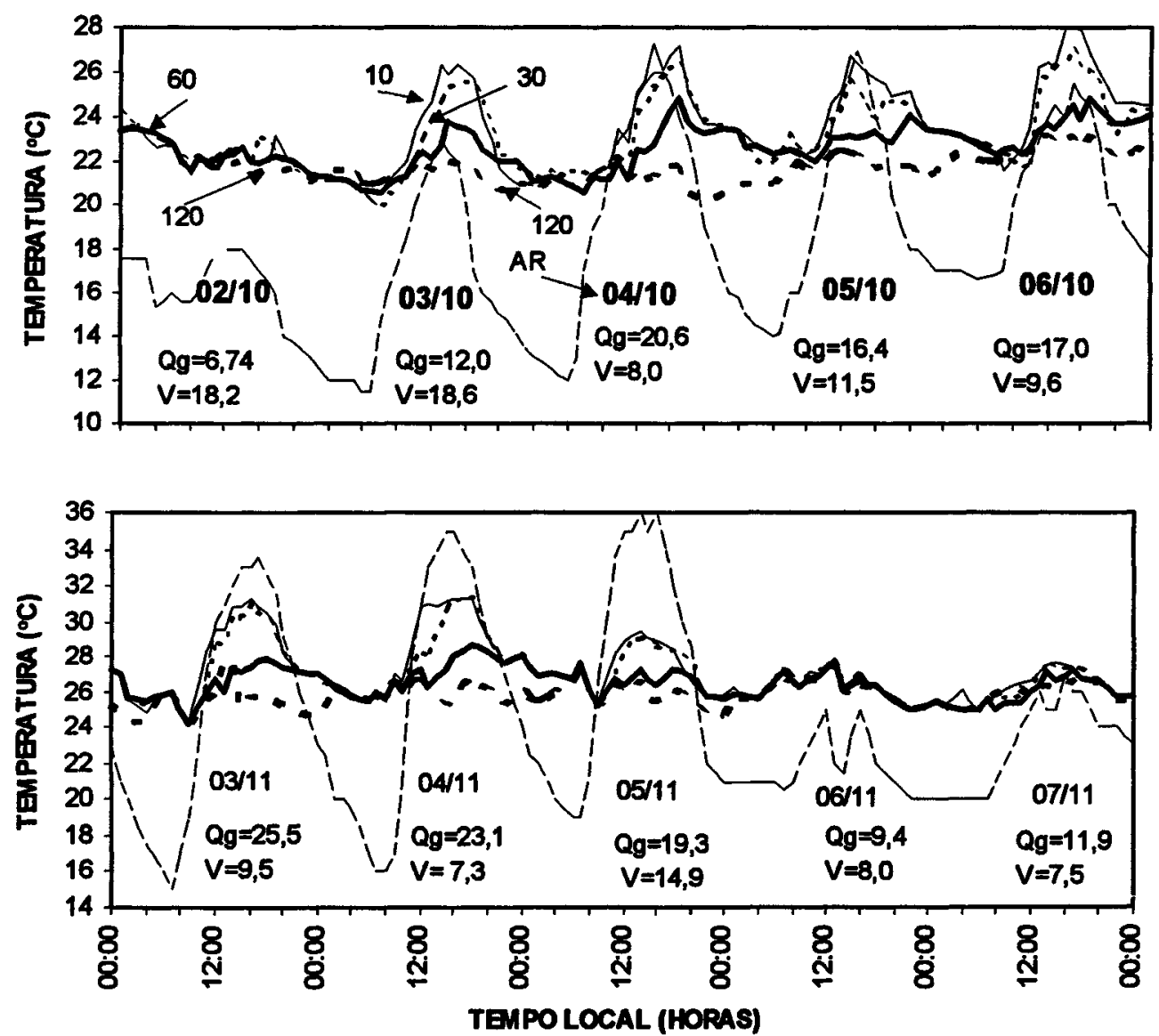

Figura 1. Variação horária da temperatura do ar e da agua em várias profundidades $(10,30,60 \mathrm{e} 120 \mathrm{~cm})$, valores de irradiância global $\left(\mathrm{Qg}\right.$, em MJ m${ }^{-2}$ dia $\left.^{-1}\right)$ e velocidade média do vento $\left(V \mathrm{em} \mathrm{km} \mathrm{h}^{-1}\right)$ em séries de dias em 1987. 
as quatro profundidades, tendo a temperatura do lago mantendo-se vários graus acima da do ar durante todo o dia. No dia seguinte, de alta irradiância, durante parte do perfodo diurno, a temperatura da água foi superior à do ar, tendo a temperatura máxima no lago atingido vários graus acima da do ar a 10 e a $30 \mathrm{~cm}$, mantendo-se a temperatura máxima na profundidade de $60 \mathrm{~cm}$ um pouco acima e a de $120 \mathrm{~cm}$ abaixo da do ar. $A$ sequência seguinte de dias de alta irradiância fez com que os valores máximos no lago, nas duas profundidades mais superfíciais, aproximassem-se da do ar, enquanto nas duas outras profundidades eles foram inferiores. No dia $06 / 10$ as máximas das duas profundidades menores voltaram a ser superiores à do ar. A temperatura mínima em qualquer profundidade ficou sempre acima da do ar em qualquer época do ano.

Para novembro, a sequência quanto à variação da irradiância solar ao longo dos dias mostrados é inversa à ocorrida para o mes de outubro, causando os padrões de variação nos quais a temperatura máxima diária do ar tendeu a manter diferenças crescentes com a da água, culminando com diferença enorme entre a temperatura do ar $\mathrm{e}$ do lago no período diurno no dia 05 , terminando por apresentar no dia 06/11 o padrão típico de um dia de baixa irradiância solar e com chuva.. Outros padrões são mostrados para dias de outono (abril) e de inverno (julho). Como esperado, a flutuação maior nas 24 horas ocorreu nas profundidades de 10 e $30 \mathrm{~cm}$, em função da absorção da radiação solar, mas enquanto em muitos dias a amplitude térmica diária atingiu valores acima de $15^{\circ} \mathrm{C}$, na água ela variou entre $6,5^{\circ} \mathrm{C}$ na profundidade de 10 $\mathrm{cm}$ e $4,0^{\circ} \mathrm{C}$ no fundo do lago, nos meses de novembro e dezembro. Nos meses de outono, as flutuações nas profundidades menores tenderam a diminuir, para se tornarem mínimas no inverno.

Durante o período noturno, o padrão genérico observado foi a diminuição das diferenças térmicas entre as quatro profundidades, em vista da perda de calor pelas camadas menos profundas. Em parte dos dias observou-se que nas duas
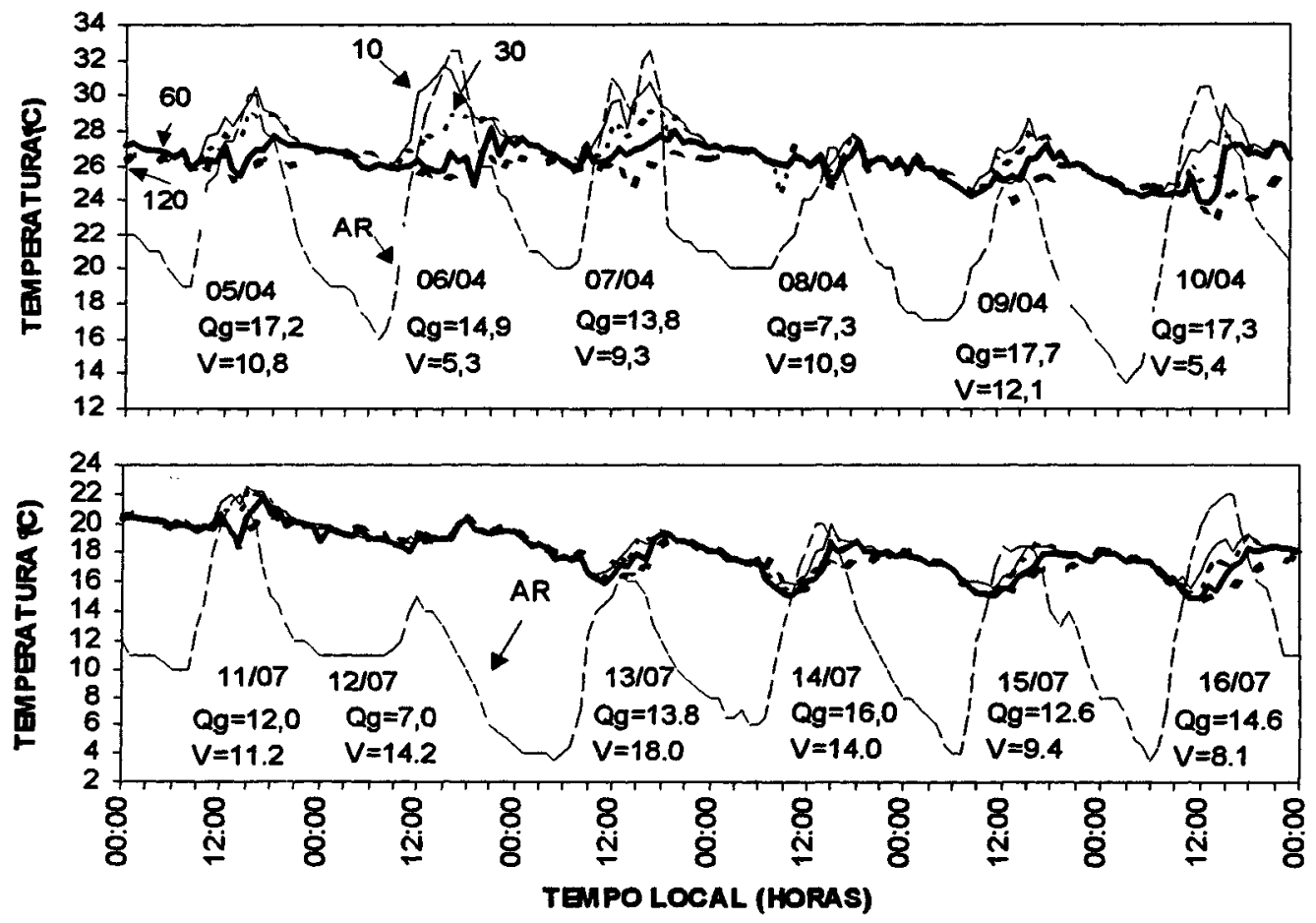

Figura 2. Variação horária da temperatura do ar e da água em várias profundidades $(10,30,60 \mathrm{e} 120 \mathrm{~cm})$, valores de irradiância global $(\mathrm{Qg}, \mathrm{em} \mathrm{MJ} \mathrm{m-2} \mathrm{dia-1)} \mathrm{e} \mathrm{velocidade} \mathrm{média} \mathrm{do} \mathrm{vento} \mathrm{(V} \mathrm{em} \mathrm{km} \mathrm{h}-1)$ em séries de dias em 1988. 
profundidades menores a temperatura tendeu a ter valores inferiores do que a das camadas mais profundas no período noturno, sendo que no final da madrugada nas quatro profundidades houve tendência de as temperaturas se igualarem, conduzindo à isotermia na coluna d'água e desestratificação térmica. Em corpos d'água poucos profundos e pequenos, pode ser observada marcante estratificação térmica durante o período diurno em dias de alta irradiância solar e com calmarias (BOYD, 1984); ESTEVES (1988) informa que em lagos tropicais é normal o desenvolvimento de estratificação térmica durante o período diurno e desestratificação durante o noturno.

Nas profundidades de 10 e $30 \mathrm{~cm}$ o curso da temperatura da água ao longo do período diurno em dias de alta irradiância solar refletiu a variação desta última, devido ao fato de ser a maior parte da energia solar absorvida nas camadas superiores de água, mas com defasagem temporal na ocorrência das máximas nas duas profundidades. A variação nas duas maiores profundidades de medida foi algo errática, principalmente no fundo do lago, já que na profundidade de $60 \mathrm{~cm}$ visualiza-se em muitos dias a temperatura máxima da água ocorrendo em consequência do regime de radiaçào solar, embora com grande defasagem em relação ao horário da máxima irradiância. Esses padrões indicam que durante o período diurno, a condução calorífica pode ter desempenhando um papel importante no processo de aquecimento das camadas mais superficiais do lago até a profundidade de $60 \mathrm{~cm}$. Entretanto, a condutividade térmica da água $\varepsilon$ pequena e o processo mais eficiente de transporte de calor na massa líquida ocorre por redistribuição da própria massa de água (BRANCO, 1986; WHEATON, 1987; ESTEVES, 1988), um processo dependente dos ventos, que ao atuarem sobre a superfície liquida promovem turbulência da água e redistribuição de calor, bem como a presença ou ausência de camadas com diferentes densidades da água (ESTEVES, 1988). Nas camadas mais profundas, essa redistribuição convectiva do calor É mais eficiente e, por não refletir diretamente o efeito do regime de radiacão solar e sim de outros fatores, como velocidade do vento e morfometria do lago, pode explicar os padrões de variação de temperatura observados nas profundidades de $10 \mathrm{e}$ $30 \mathrm{~cm}$ durante o período diurno e em toda a coluna de água durante o periodo noturno.
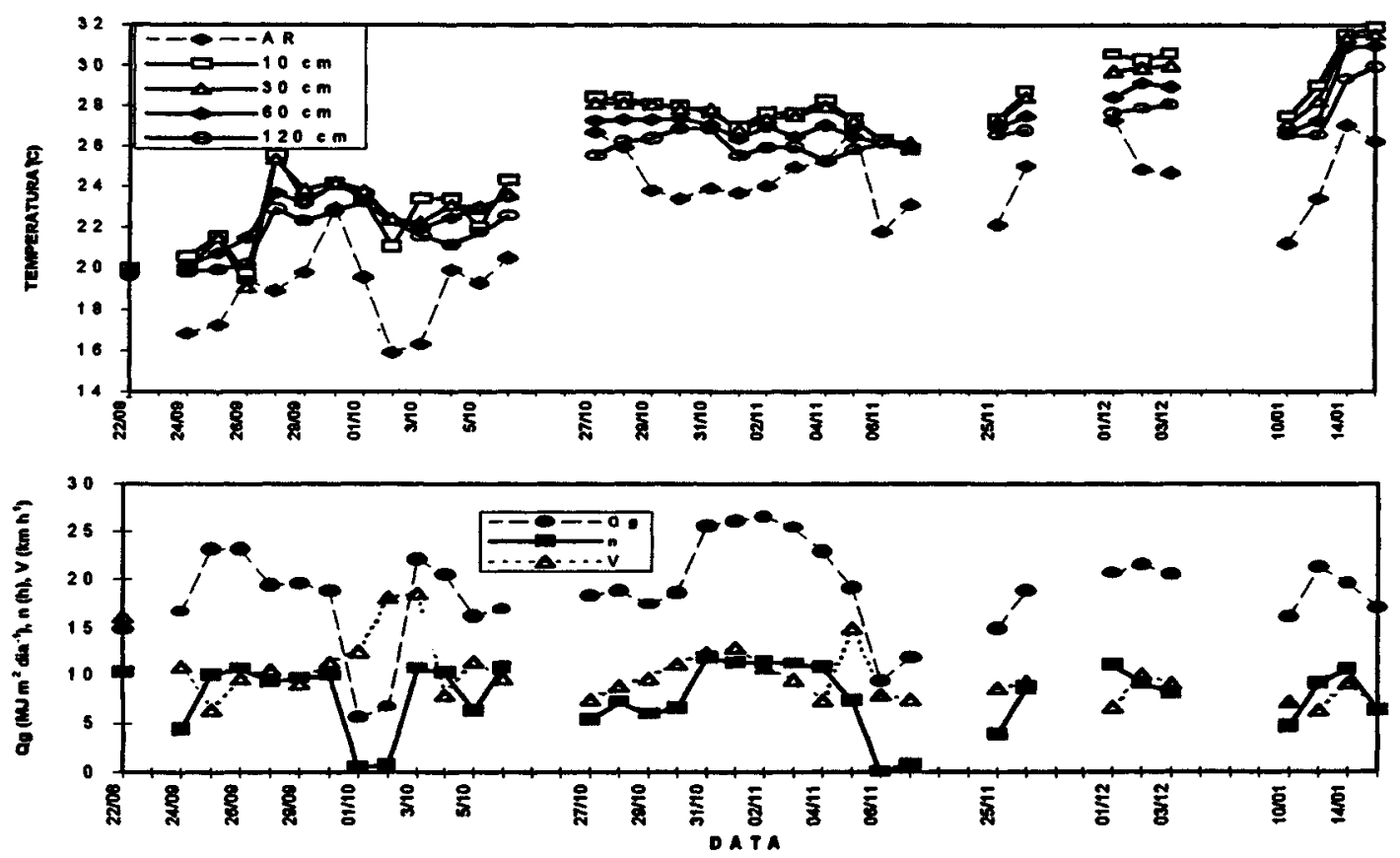

Figura 3. Variação ao longo da primavera e verão de $1987 / 88$ de valores diários de temperatura média da água nas várias profundidades e do ar, da velocidade média do vento (V), da irradiancia solar global (Qg) e do número de horas de brilho solar (n). 
$O$ efeito do vento no sentido de diminuir o grau de estratificação térmica da coluna de água pode ser percebido em alguns dos dias mostrados. Por exemplo, a diferença entre as temperaturas diurnas nas profundidades de 10 e $30 \mathrm{~cm}$ foi menor no dia 05/04 do que no dia seguinte, embora no primeiro dia a irradiância global fosse maior, mas tendo a velocidade média do vento sido o dobro no primeiro desses dias.

A estratificação térmica em dias sem nebulosidade foi mais acentuada nos meses de verão, tendo a máxima diferença térmica diária entre a profundidades superior $e$ inferior de medida sido de $6,7^{\circ} \mathrm{C}$ no mês de dezembro no período da tarde. A máxima diferença térmica entre essas duas profundidades, em dias ensolarados, tendeu a diminuir atingindo no mês de julho valores menores, normalmente $\mathrm{da}$ ondem de $2^{\circ} \mathrm{C}$, mas ocorrendo em um dia a diferença de $4^{\circ} \mathrm{C}$ nesse mês.

Considerando valores extremos, as temperaturas máximas absolutas em cada profundidade ocorreram no dia 17/01/88, sendo de $37,2^{\circ} \mathrm{C}$ a $10 \mathrm{~cm}$ (as 16 horas), de $36,1^{\circ} \mathrm{C}$ a $30 \mathrm{~cm}$ (as 17 horas), de $34,4^{\circ} \mathrm{C}$ para $60 \mathrm{~cm} \mathrm{e} 32,1^{\circ} \mathrm{C}$ para
$120 \mathrm{~cm}$ (ambas as 22 horas), com temperatura máxima do ar de $35,2^{\circ} \mathrm{C}$. As temperaturas mínimas da água ocorreram em $16 / 07$, sendo de $15,6^{\circ} \mathrm{C}$, $14,8^{\circ} \mathrm{C}, 14,8^{\circ} \mathrm{C}$ e $14,5^{\circ} \mathrm{C}$, respectivamente para as profundidades de $10,30,60 \mathrm{e} 120 \mathrm{~cm}$, no horário das 11 horas para as tres primeiras e das 12 horas para a de $120 \mathrm{~cm}$, valores bem acima da mínima do ar.

\section{Variações da temperatura média diária ao longo do ano}

As figuras 3 e 4 mostram os valores médios diários de temperatura da água em cada profundidade e a do ar, obtidos, em dias nos quais havia a série completa de medidas nas 24 horas. Os valores representam a média simples obtida a partir dos valores observados a intervalos de 1 hora. São mostrados, também, os valores diários de irradiância solar global $(\mathrm{Qg})$, do número de horas de brilho solar e da velocidade média do vento.

A figura 3 mostra as flutuações ocorridas entre agosto de 1987 e janeiro de 1988, com tendência sazonal de aumento da temperatura média
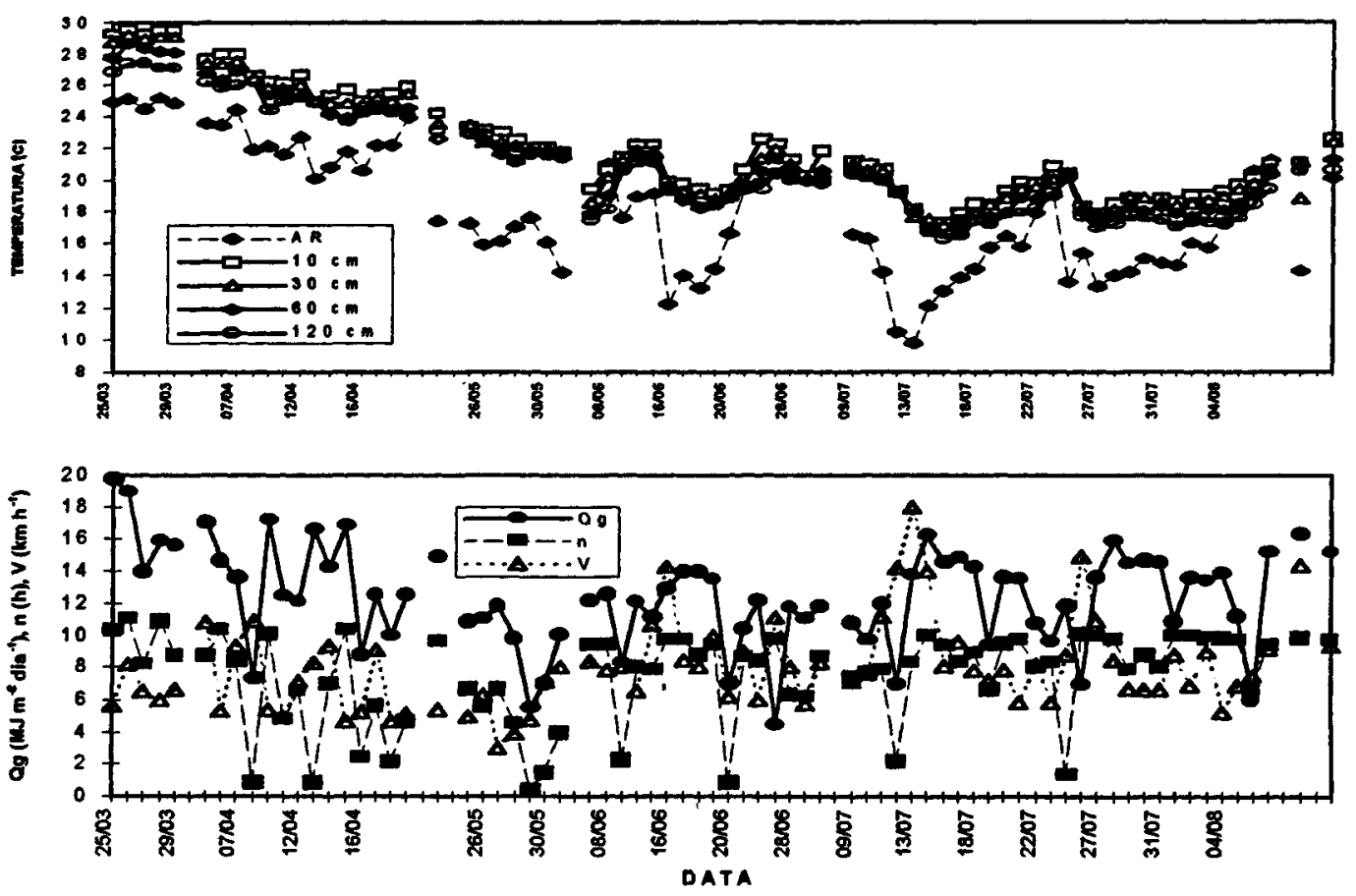

Figura 4. Variação ao longo do outono e inverno de 1988 de valores diários de temperatura média da água nas várias profundidades e do ar, da velocidade média do vento $(V)$, da irradiância solar global $(Q g)$ e do número de horas de brilho solar (n). 
da água e do ar. A temperatura média diária da água foi sempre superior a do ar em qualquer profundidade, com exceção de tres dias $(26 / 09 ; 30$ / 09 e 27/10) no fundo do lago $(120 \mathrm{~cm}) \mathrm{e}$ em outro dia $(05 / 11)$ nas profundidades de 60 e $120 \mathrm{~cm}$, onde ocorreu o inverso. Nesses meses, o vento e a irradiância solar global, os elementos meteorológicos com maior influência, apresentaram valores médios cujas diferenças em relação às médias históricas foram menores que os desvios padrões dessas médias, podendo-se considerá-los como meses típicos quanto a esses elementos meteorológicos. Os maiores desvios observados foram altura pluviométrica inferior à média histórica em outubro, com diferença entre ambas maior que o desvio-padrão da série e temperatura média do ar superior em $1,3^{\circ} \mathrm{C}$ à média histórica, ligeiramente acima do desvio padrão de $1,0^{\circ} \mathrm{C}$ para o mês. Assim, pode-se considerar que os valores observados entre agosto 87 e janeiro 88 representam bem o regime térmico médio do lago para esses meses, ao longo dos anos.

A estratificação térmica nesse período foi evidente, tendo as temperaturas médias da água diminuido sistematicamente das profundidades maiores para as menores, com exceção de alguns dias em que a irradiância solar foi baixa em sequência a outros dias de baixa irradiância. Nesses dias houve tendência de homogeneização da temperatura na coluna d'água, ocorrendo até mesmo menor temperatura média na profundidade de $10 \mathrm{~cm}$, como no dia $02 / 10$. As menores temperaturas médias da água ocorreram no dia 221 08 (entre 20,0 e $19,6^{\circ} \mathrm{C}$, dependendo da profundidade) e as maiores no dia $15 / 01$ (31,9; 31,$5 ; 30,9$ e $29,9^{\circ} \mathrm{C}$, respectiva e ordenadamente da menor para a maior profundidade). As diferenças de temperatura média diária entre a menor e a maior profundidade variou entre $0,2^{\circ} \mathrm{C}$ em dia de baixa irradiância e vento moderado (média $10 \mathrm{~km} \mathrm{~h}^{-1}$ ) a $2,7^{\circ} \mathrm{C}$ em dia de alta irradiância, dias esses subsequentes a outros de céu limpo. As diferenças entre as temperaturas médias da água e da do ar chegaram aos valores extremos de $6,7^{\circ} \mathrm{C}$ na profundidade de $10 \mathrm{~cm}$ e $4,0^{\circ} \mathrm{C}$ na de $120 \mathrm{~cm}$.

A figura 4 mostra as variações dos valores médios para os meses de outuno e inverno. Nos meses de fevereiro, março e abril, os desvios dos valores de irradiância global em relação à média histórica foram ligeiramente maiores que os desviospadrões observados na série histórica, o mesmo ocorrendo com velocidade média do vento no mês de junho. Foram observados desvios entre $2,2^{\circ} \mathrm{C} \mathrm{e}$ $1,7^{\circ} \mathrm{C}$ acima da média histórica da temperatura do ar e valores de altura pluviométrica anormalmente superiores nos meses de fevereiro, abril e maio. Embora isso possa ter condicionado um regime térmico do lago no período de medidas diferentes do seu regime médio ao longo do tempo, como os desvios maiores não ocorreram com a irradiância solar e a velocidade do vento, elementos de maior influência na temperatura da coluna d'água, os resultados obtidos neste estudo podem ser considerados como razoavelmente indicativos do regime térmico médio do lago nas duas estações ao longo dos anos.

Com diminuição da temperatura durante o transcorrer do outono e inverno, as diferenças entre as temperaturas médias diárias da agua nas diferentes profundidades tenderam a diminuir em relação ao período de agosto a janeiro, com valores inferiores a $1^{\circ} \mathrm{C}$, em média, enquanto que as diferenças entre as temperaturas médias da água e do ar permaneceram elevadas, com diferenças extremas de $8,3^{\circ} \mathrm{C}$ e $7,9^{\circ} \mathrm{C}$ nas profundidades de 10 e $30 \mathrm{~cm}$ no dia 13/07. Em boa parte dos dias, essas diferenças foram superiores a $5^{\circ} \mathrm{C}$. Os maiores valores absolutos de temperaturas extremas foram $29,2^{\circ} \mathrm{C}, 28,8^{\circ} \mathrm{C}, 27,8^{\circ} \mathrm{C}$ e $26,8^{\circ} \mathrm{C}$ no dia $25 / 03$ para as quatro profundidades (da menor para a maior, respectivamente) tendo a extrema do ar sido de $26,1^{\circ} \mathrm{C} \mathrm{em} 26 / 03$. Os menores valores foram observados em 13/07: $18,1^{\circ} \mathrm{C}, 17,7^{\circ} \mathrm{C}, 18,0 \mathrm{e}$ $17,9^{\circ} \mathrm{C}$ para a água, para média do ar de $9,8^{\circ} \mathrm{C}$.

As informações obtidas servem como subsídio à aquacultura e ao manejo de animais de hábito anfibio, pois permitem uma avaliação das variaçòes térmicas esperadas ao longo de um ano em pequenos corpos d'água na regiāo, auxiliando na definição da aptidão física do ambiente para o desenvolvimento dessas atividades, com o apôio dos trabalhos básicos sobre o comportamento termorregulador de cada espécies de interesse.

\section{CONCLUSÕES}

As amplitudes térmicas diárias da água nas diferentes profundidades foram bem menores do que as do ar. A temperatura do lago manteve-se na maior parte do dia acima da do ar em dias de alta irradiância; em dias muito nublados ou chuvosos isso ocorreu nas 24 horas. No período compreendido entre agosto e janeiro, as diferenças de temperatura entre as diferentes profundidades 
na água foram mais acentuadas, atingindo diferenças entre a maior e menor profundidades de ate $6,7^{\circ} \mathrm{C}$, com maior estratificação do que no outono e inverno. As temperaturas máximas absolutas da água ocorreram em meados de janeiro, com valores entre $37,2^{\circ} \mathrm{C}$ na profundidade de $10 \mathrm{~cm}$ e $32,1^{\circ} \mathrm{C}$ na de $120 \mathrm{~cm}$, com mínimas absolutas entre $15,6^{\circ} \mathrm{C}$ e $14,5^{\circ} \mathrm{C}$ nessas profundidades, em meados de julho. As temperaturas médias diáriàs da água aumentaram, então, até o mês de janeiro, diminuindo a partir de março, mantendo-se acima da do ar com raras exceçôes e com valores extremos na menor profundidade de medida de $6,7^{\circ} \mathrm{C}$ no verão e $8,3^{\circ} \mathrm{C}$ no inverno. Os valores extremos absolutos das médias diárias foram, respectivamente da menor para a maior profundidade: $31,9^{\circ} \mathrm{C}$, $31,5^{\circ} \mathrm{C}, 30$ e $29,9^{\circ} \mathrm{C}$, em meados de janeiro e $18,1^{\circ} \mathrm{C}, 17,7^{\circ} \mathrm{C}, 18,0^{\circ} \mathrm{C}$ e $17,9^{\circ} \mathrm{C}$ em meados de julho.

\section{REFERÊNCIAS BIBLIOGRÁFICAS}

BOYD, C.E. Water Quality in warmwater fish ponds. Auburn University Agricultural Experiment Station, 1984. 359p.
BRANCO, S.M. Hidrobiologia aplicada à engenharia sanitaria. CETESB/ASCETESB, 1986. 616p.

ESTEVES, F.A. Fundamentos de limnologia. São Paulo: Intersciência/FINEP, 1988. 575p.

HARDY, R.N. Temperatura e vida animal. São Paulo: E.P.U./E.D.U.S.P. 1981. 91 p.

LANG, J. Crocodilian selection. In: Webb, G.J.W.; Manolis, S.C. \& Whiteheld, P.J. (Eds.) Wildlife management: crocodiles and alligators. Chipping Norton: Surrey Beatty \& Sons, 1987, p. 301-317.

VERDADE, L.M.; PACKER, I.U.; MICHELLOTI, F.; RANGEL, M.C. Thermoregulatory behavior of broadsnouted caiman (Caiman latirostris) under different thermal regimes. In: 3rd WORKSHOP ON CONSERVATION AND MANAGEMENT OF THE BROAD-SNOUTED (Caiman latistrosis). São Paulo, 1992, p. 84-92.

Recebido para publicação em 05.03.95 Aceito para publicação em 07.05.95 